\title{
Stem cell transplantation therapy for diabetic foot ulcer: a narrative review
}

\author{
Sahar Shafiee ${ }^{1,2}$, Maryam Heidarpour ${ }^{3 \odot}$, Sima Sabbagh ${ }^{1,2 \odot}$, Elham Amini ${ }^{1,2 \odot}$, Hanieh Saffari ${ }^{2 \odot}$, \\ Sara Dolati ${ }^{\circledR}$, Rokhsareh Meamar ${ }^{1, *} \odot$
}

\begin{abstract}
Diabetes mellitus is a chronic metabolic disease associated with high cardiovascular risk. A vascular complication of diabetes is foot ulcers. Diabetic foot ulcers are prevalent and substantially reduce the quality of life of patients who have them. Currently, diabetic foot ulcer is a major problem for wound care specialists, and its treatment requires considerable health care resources. So far, various therapeutic modalities have been proposed to treat diabetic foot ulcers and one of them is stem cell-based therapy. Stem cell-based therapy has shown great promise for the treatment of diabetic foot ulcers. This strategy has been shown to be safe and effective in both preclinical and clinical trials. In this review, we provide an overview of the stem cell types and possible beneficial effects of stem cell transplantation therapy for diabetic foot ulcers, and an overview of the current status of stem cell research in both preclinical and clinical trial stages of treatment strategies for diabetic foot ulcers.
\end{abstract}

Keywords: diabetes complications; diabetic angiopathies; diabetic foot; stem cell transplantation; wound healing

Diabetes mellitus (DM), a metabolic syndrome, refers to a hyperglycemic state in which insulin secretion is either deficient or resistant, or both. Hyperglycemia is a chronic disorder accompanying long-term damage to various organs in the human body, in particular ophthalmic, renal, nervous, and cardiac organs, and causes endothelial dysfunction or failure [1]. It is estimated that about $5 \%$ of the global population lives with diabetes [2]. A systematic review of DM prevalence showed a range of $3 \%-20 \%$ in different provinces in Iran [3]. Diabetic foot syndrome is a chronic condition of DM with severe and devastating complications [4]. The syndrome is defined as a foot abnormality associated with several pathologies, including peripheral neuropathy, microangiopathy, and other consequences of metabolic disturbances. About $7 \%-15 \%$ of diabetic patients have diabetic foot ulcers [2]. Furthermore, about $5 \%-24 \%$ of patients with these ulcers undergo amputation of their lower extremities within 6-18 months of their first examination, and 50\% of amputees ultimately die within 5 years [5]. Mortality and morbidity due to ulcers have a profound effect on national and individual finances and health care systems [2]. According to an International Working Group on Diabetic Foot, the risk of ulcer rises with increasing age, duration of DM, and blood level of $\mathrm{HbA}_{1 \mathrm{c}}$ [6]. To mitigate and control the devastating complications

*Correspondence to: Rokhsareh Meamar, Isfahan Clinical Toxicology Research Center, Isfahan University of Medical Sciences, Isfahan 81746-73461, Iran, e-mail: meamar@pharm.mui.ac.ir

${ }^{1}$ Isfahan Clinical Toxicology Research Center, Isfahan University of Medical Sciences, Isfahan 81746-73461, Iran

${ }^{2}$ Clinical Development Research Center, Islamic Azad University, Najafabad Branch, Isfahan 81737-35131, Iran

${ }^{3}$ Isfahan Endocrine and Metabolism Research Center, Isfahan University of Medical Sciences, Isfahan 81737-35131, Iran

כ Open Access. (c) 2021 Shafiee et al., published by Sciendo. (c))BY-NC-ND This work is licensed under the Creative Commons Attribution NonCommercial-NoDerivatives 4.0 License. 
of diabetes, the current environment of multidisciplinary management necessitates innovative therapeutic strategies [7].

The current standard foot ulcer therapy includes offloading, foot infection control, ischemia control, improvement of metabolic abnormalities, wound debridement, and wound care dressing [8]. Nonetheless, ulcer treatment requires a considerable time to process during which the majority of diabetic sufferers fail to recover and appear doomed to a cycle of foot ulcer, gangrene, and limb amputation [5]. Thus, the ulcer healing process should be accelerated by devising innovative therapeutic methods, such as stem cell therapy. Stem cell therapy has produced encouraging results for the treatment of ulcers in both animal models and humans [9]. Despite the apparent efficacy of stem cell therapy shown by primary research, such results cannot be successfully interpreted or generalized to all cases due to the diversity of research methodologies. Hence, the standardization of stem cell therapy for ulcer treatment is demanding [7]. The present study is focused to review the effect of stem cell therapy for treating ulcers both in animal models and humans with emphasis on the type and origin of stem cells as well as routes of cell administration.

\section{Methods}

A full search of English-language sources including EMBASE, MEDLINE, SCOPUS, and Web of Science was conducted mostly with controlled keywords (i.e., terms found in medical subject headings). The terms were coordinated with the U.S. National Center for Biotechnology Information MeSH database. Relevant keywords used were "diabetes mellitus," "diabetic foot," "foot ulcers," "stem cells," "wound healing" or "wound treatment," "cell therapy," "mesenchymal stem cells (MSC)," "embryonic stem cells," "adult stem cells," "induced pluripotent stem cells (iPSCs)," "umbilical cord-derived mesenchymal stem cells (UCMSC)," "cord blood stem cell transplantation," "mesenchymal stem cells," "adipose-derived (mesenchymal) stem cell," "hematopoietic stem cells," "clinical trial," and "molecular mechanism." We prioritized the references published within the past 10 years. An article was excluded if it met any of the following criteria: duplicates; no English or Persian abstract; no full text; not relevant to ulcers (for example ulcer induced with other diseases, such as Buerger disease, infections, renal disease, and pressure-induced ulcers); and stem cells that are not utilized in ulcers (such as, neural stem cells). The selected articles were retrieved and assessed in the full text. We included review articles and also searched the bibliographies of the retrieved articles. The literature was screened and selected using the strategy presented below.
Three research assistants working part-time at the Isfahan Clinical Toxicology Research Center, Isfahan University of Medical Sciences, and Clinical Development Research Center, Islamic Azad University, and 2 medical students who are also members of the Clinical Development Research Center, Islamic Azad University, Najafabad branch, Isfahan, Iran, selected and screened the articles. They were educated to understand the objectives of this review, the conceptual framework, and the inclusion and exclusion criteria for article screening. The title and abstract of the screened articles were scrutinized and classified as "included," "excluded," and "uncertain." An article was included only if there was a consensus between screeners to categorize it as "included." Lack of consensus among authors was resolved by the corresponding author using her personal experience.

\section{Types of stem cells}

Stem cells have the unique capacity to become new stem cells (self-renew) or specialized cells (differentiation) with different specific functions, such as brain cells, bone cells, blood cells, or heart muscle cells.

Several stem cell classifications have been defined. However, generally, stem cells can be divided into 2 main categories: "pluripotent" stem cells (induced pluripotent and embryonic stem cells) and somatic or nonembryonic stem cells (commonly called "adult stem cells"). Pluripotent stem cells can differentiate into any cells of the adult body. Somatic stem cells are found in organs and can differentiate to yield an organ's specialized cell type. Embryonic stem cells are derived from the inner cell mass of a blastocyst within 4-5 days postfertilization [10]. The subtypes of adult stem cells include hematopoietic stem cells, mesenchymal stromal stem cells, neural stem cells, and muscle stem cells that are categorized based on tissue origin [7]. Adult stem cells are considered critical therapeutic elements in regenerative medicine due to their inherent potential to differentiate into various cell types and their frequent presence in body tissues.

\section{Mechanism of action of stem cells in treatment of diabetic foot ulcers}

Stem cells are capable of targeting, as well as bypassing abnormal healing mechanisms and disorganized cell signaling in diabetic foot ulcers. In this regard, stem cells are considered a promising treatment of the ulcers [11]. As a complex and dynamic process, wound healing undertakes certain critical procedures such as angiogenesis, neovascularization, 
and the release of growth factors that are impaired in diabetic patients [12].

The various potentials of stem cells [10] include antiinflammatory and neoangiogenic effects, secretion of numerous growth factors, and differentiation into various cell types that are involved in the wound healing process [6]. The precise mechanisms of action of stem cells in wound healing are not yet fully understood. Stem cells act through 2 mechanisms. First, they attenuate the inflammatory response, and second, they differentiate into cells involved in wound healing, including myofibroblasts, fibroblasts, antigen-presenting cells, and endothelial progenitor cells [13]. Accordingly, the stem cells differentiate into various cell types, form new capillaries that participate in vascular renewal to resolve ischemia and restore blood flow in the lower extremities [14]. Chronic diabetic wounds are less likely to heal thoroughly due to a lack of an adequate blood supply. However, chronic ulcers can be healed through granulation and epithelial metaplasia as the most important mechanism of stem cell treatment [15].

The underlying mechanisms are not yet clear. All stem cells share essential biological properties; and they may contribute to a core of molecular regulatory pathways [16]. By contrast, differences in the wound healing response may result from intrinsic differences between diverse stem cells, such as the expression of the different transcription factors or different properties of stem cell niches, and consequently, these factors regulate the maintenance of some stem cells, but not others [17]. We will discuss the specific mechanisms related to the specific stem cells in detail separately.

\section{Stem cells and diabetic foot ulcers}

\section{Mesenchymal stem cells}

Mesenchymal stem cells, also known as fibroblast-like nonhematopoietic stem cells, have been isolated from bone marrow. Mesenchymal stem cells are copiously amassed in adipose tissue, cartilage, bone tissue, umbilical cord blood, and placentas [18]. These cells can differentiate into adipocytes, chondrocytes, and osteocytes in vitro once being treated with differentiation-inducing agents [18].

Mesenchymal stem cells typically express markers such as CD90, CD105, and CD73; however, the lack of expression of CD14, CD34, and CD45 is also a characteristic. These cells have received significant attention for cell therapy [19]. One of the most effective therapies for chronic nonhealing ulcers is the autologous implantation of bone marrow mesenchymal stem cells [20]. A unique feature of mesenchymal stem cells is their action as repair cells, a term that refers to the ability of mesenchymal stem cells to become specialized cells only when necessary [21].

The application of autologous bone marrow mesenchymal stem cells is practically advantageous in various aspects. First, mesenchymal stem cells can be readily segregated from bone marrow, even in patients with progressive disease and cell-lineage commitment (targeting differentiation). Second, mesenchymal stem cells can be expanded and enriched in vitro despite their small concentration in the bone marrow compartment. Third, graft rejection can be prevented without any immunosuppressive treatment. Finally, this type of adult stem cell is less subject to malignant changes and genetic abnormalities [11]. By contrast, the disadvantages of using mesenchymal stem cells are limited differentiation potential, cell concentration, cellular performance affected by comorbidities, and the high risk of surgical biopsy [11]. In addition, bone marrow mesenchymal stem cells may associate with the impairment of proliferation, and differentiation and antiapoptotic properties of cells in diabetic patients [11, 12].

Bone marrow mesenchymal stem cells have been found to be beneficial for accelerated wound healing mainly through paracrine function [12]. These cells improved wound healing by increasing the amounts of growth factors at the injury site, enhancing granulation tissue formation, and promoting migration, angiogenesis, and re-epithelialization [12]. Investigations of the effect of various rehabilitation factors showed that they significantly increased both the secretion of vascular endothelial growth factor (VEGF) [22-24] and the density of blood vessels [23]. Moreover, mesenchymal stem cells play an important role in reducing the inflammatory, proliferative, and remodeling phase of wound healing, which subsequently leads to several healthy physiological functioning and successful treatments [25]. In the presence of mesenchymal stem cells, the ability of activated macrophages to secrete inflammatory factors may be attenuated; however, the release of antiinflammatory molecules helped to improve cell survival [26]. These cells could increase the pace of epithelialization, as well as enhance granulation tissue formation, epidermal cell growth, migration, collagen deposition, and promote resolution of wound inflammation. However, the therapeutic potential of mesenchymal stem cells in the treatment of diabetes becomes remarkable considering their capability to differentiate into cells that can secrete insulin and c-peptide in reaction to elevated blood glucose [27].

According to some studies, wound size reduced after bone marrow mesenchymal stem cell treatment $[22,23,28$, 29]. Similarly, improvements in painless walking time, ulcer healing, and lower limb perfusion were found by other studies [20, 30-32]. Moreover, successful culture, characterization, and use of cultured autologous bone marrow mesenchymal 
stem cells in nonhealing lower-extremity ulcers were observed [20].

Some clinical trials and case reports provide evidence that therapeutic administration of mesenchymal stem cells enhanced the process of wound healing in clinical settings [20, 30, 31, 33-36] (Table 1).

Alternatively, mesenchymal cells are commonly derived from umbilical cord blood and peripheral blood due to the relative ease of the cell harvest [18]. Mesenchymal stem cells originating in the human umbilical cord blood have superior potential to differentiate and amplify than the stem cells derived from bone marrow or autologous peripheral blood [47]. Moreover, human umbilical cord blood mesenchymal stem cells are associated with lower immunogenicity and lower malignancy risk, and better access through donor umbilical cord blood banking by which adequate cell numbers can be obtained [48]. In addition, these cells can be used to confer ideal human leukocyte antigen matching [49]. These cells can be generated on a large scale as they can be expanded up to 4 times the original number of cells within 3-5 days in vitro under suitable cell culture conditions [50].

A few studies have investigated the clinical application of human umbilical cord mesenchymal stem cells to tissue repair caused by pathological conditions. The dynamic balance of the mesenchymal stem cell secretome, cell source, purity, and preconditioning can influence the angiogenic properties of various mesenchymal stem cells [51]. The crucial role of human umbilical cord mesenchymal stem cells in generating new blood capillaries cannot be overlooked. Therefore, such cells may suitable for the treatment of foot ulcer in diabetic patients with lower extremity vascular and arterial diseases [14]. A rat model of diabetic foot ulcer receiving human umbilical cord mesenchymal stem cells via the femoral artery has shown that the localization of umbilical cord-derived mesenchymal stem cell in the target area was feasible by using the expression of human leukocyte antigen-1 as a marker to track umbilical cord-derived mesenchymal stem cells in vivo [52]. Umbilical cord-derived mesenchymal stem cells reduced the size of foot ulcers in the rat model and enhanced the epithelialization of damaged tissue through both cytokeratin 19 released from keratinocytes and the formation of extracellular matrix [52]. Further studies of ulcers in the rat model found that application of umbilical cord-derived mesenchymal stem cells improved vascular density [23], accelerated wound healing function, and repaired sensory function [53] through the expression of growth factors including VEGF, keratinocyte growth factor, platelet-derived growth factor, and brain-derived growth factor [54]. The correction of immunological anomalies in patients with diabetes further supports the clinical application of these cells to complications of
DM [37]. Li et al. [37] found the improvement of ulcers in patients following human umbilical cord mesenchymal stem cell transplantation was associated with significantly reduced levels of blood glucose levels and insulin dosage. In 2 clinical trials, improvement of outcome with vascular angioplasty was shown in patients with ulcers $[14,55]$. In Table $\mathbf{1}$, the results of clinical trials using umbilical cord-derived mesenchymal stem cells are presented.

\section{Adipose-derived stem cells}

Zuk et al. [56] pioneered the isolation of new adult stem cells, namely adipose-derived stem cells. As these cells are similar to bone marrow mesenchymal stem cells, they are known as adipose mesenchymal stem cells [57]. Adipose-derived mesenchymal stem cells are found in subcutaneous tissue. Like the umbilical cord blood-derived stem cells described above, adipose-derived stem cells secreted growth factors, cytokines, and type-I collagen in culture [58]. Such attributes of diabetic adipose-derived stem cells make them a potential cell source for wound closure and restoration [59].

Adipose tissue-derived mesenchymal stem cells can be obtained with lower risk than bone marrow mesenchymal stem cells, making adipose tissue a major source of stem cells [57]. Large quantities of cells can be extracted with minimal side effects at the donor site. Because isolated adipose-derived stem cells can be cryopreserved for up to 6 months, they provide easy and immediate availability for treatment [60]. The advantages of adipose-derived stem cells include their relatively easy isolation, rapid expansion, donor-specificity, lower risk for malignancy, cell-lineage commitment, lack of ethical conflicts, and tissue disposability after liposuction, lower surgical risk, and lower donor morbidity compared with bone marrow mesenchymal stem cells [48]. Although adiposederived stem cells have similarities with bone marrow mesenchymal stem cells, more definite angiogenic and regenerative potentials in adipose-derived stem cells have been observed when compared directly with bone marrow mesenchymal stem cells in a model of limb ischemia [61]. These differences could be accredited to a more potent paracrine activity of adipose-derived stem cells than that of bone marrow mesenchymal stem cells [62]. The difficulty of tissue degradation to extract adipose-derived stem cells is a main limitation to the use of adipose tissue as a source of stem cells because of the lack of commercially-available enzymes for adipose tissue digestion [11].

The transplantation of adipose-derived stem cells can significantly enhance ulcer healing in a mouse model of diabetes, although the density and length of their local blood vessels 
Table 1. Human studies using stem cell transplantation for the treatment of diabetic foot ulcer

\begin{tabular}{|c|c|c|c|c|c|c|c|}
\hline $\begin{array}{l}\text { Reference, } \\
\text { country }\end{array}$ & $\begin{array}{l}\text { Number of } \\
\text { patients }\end{array}$ & $\begin{array}{l}\text { Administration } \\
\text { route }\end{array}$ & $\begin{array}{l}\text { Follow-up } \\
\text { duration }\end{array}$ & $\begin{array}{l}\text { Treatment } \\
\text { duration }\end{array}$ & Cell type & Dosage & Outcome \\
\hline $\begin{array}{l}\text { Vojtaššák } \\
\text { et al. [35] } \\
2006, \\
\text { Slovakia }\end{array}$ & $\begin{array}{l}\text { A 77-year- } \\
\text { old diabetic } \\
\text { patient }\end{array}$ & $\begin{array}{l}\text { Injected into } \\
\text { the edges of the } \\
\text { wound }\end{array}$ & 29 days & $\begin{array}{l}7 \text { days and } \\
17 \text { days }\end{array}$ & $\begin{array}{l}\text { BM-MSCs with } \\
\text { autologous skin } \\
\text { fibroblasts on } \\
\text { biodegradable } \\
\text { collagen } \\
\text { membrane }\end{array}$ & $\begin{array}{l}\left(3 \times 10^{6} \text { of cells }\right) \\
\text { were set onto a } \\
\text { surface } \\
(25 \mathrm{~mm} \times 50 \mathrm{~mm})\end{array}$ & $\begin{array}{l}\text { Improved: } \\
\text { - Vascularity of the } \\
\text { dermis } \\
\text { - Dermal thickness of } \\
\text { the wound } \\
\text { - Wound size }\end{array}$ \\
\hline $\begin{array}{l}\text { Debin et al. } \\
\text { [30] } \\
2008 \text {, China }\end{array}$ & $\begin{array}{l}\text { Patients were } \\
\text { randomized } \\
\text { into } 22 \text { cases } \\
\text { (transplanted } \\
\text { group) } 23 \\
\text { controls }\end{array}$ & $\begin{array}{l}\text { Intramuscular } \\
\text { injections }\end{array}$ & 12 weeks & 3 weeks & BM-MSCs & $\begin{array}{l}7.32 \times 10^{8} \text { to } \\
5.61 \times 10^{9} \text { at } \\
3 \mathrm{~cm} \times 3 \mathrm{~cm} \text { long } \\
\text { and } 1-1.5 \mathrm{~cm} \\
\text { deep }\end{array}$ & $\begin{array}{l}\text { Improved: } \\
\text { - Ulcer healing } \\
\text { - ABI } \\
\text { - Amputation rate } \\
\text { - Rest pain } \\
\text { - Angiogenesis } \\
\text { - Intermittent } \\
\text { claudication }\end{array}$ \\
\hline $\begin{array}{l}\text { Dash et al. } \\
\text { [20] } \\
2009 \text {, India }\end{array}$ & $\begin{array}{l}\text { Patients were } \\
\text { randomized } \\
\text { into } 3 \text { cases } \\
\text { and } 3 \text { controls }\end{array}$ & $\begin{array}{l}\text { Around ulcer, } \\
\text { covered by a } \\
\text { dressing }\end{array}$ & 12 weeks & Every 2 weeks & $\begin{array}{l}\text { Autologous } \\
\text { BM-MSCs }\end{array}$ & $\begin{array}{l}>1 \times 10^{6} \\
\text { cells from } \\
5.04 \pm 0.70 \mathrm{~cm}^{2} \text { to } \\
1.48 \pm 0.56 \mathrm{~cm}^{2}\end{array}$ & $\begin{array}{l}\text { Improved: } \\
\text { - Walking interval } \\
\text { without pain } \\
\text { - Ulcer size decrease } \\
\text { - No difference in the } \\
\text { biochemical parameters }\end{array}$ \\
\hline $\begin{array}{l}\text { Lu et al. [34] } \\
\text { 2011, China }\end{array}$ & $\begin{array}{l}\text { Patients were } \\
\text { randomized } \\
\text { into } 20 \text { pati- } \\
\text { ents (BM-MSC } \\
\text { group), } 21 \\
\text { patients } \\
\text { (BM-MNC } \\
\text { group), } \\
\text { and both } \\
\text { groups have } \\
\text { a } 1 \text { normal } \\
\text { saline group } \\
\text { as control } \\
\text { (double-blind) }\end{array}$ & $\begin{array}{l}\text { Intramuscular } \\
\text { into the inferior } \\
\text { limb ( } 20 \text { sites, } \\
3 \mathrm{~cm} \text { long, } \\
1-1.5 \mathrm{~cm} \text { deep, } \\
\text { and } 0.5-1 \mathrm{~mL} \\
\text { BM-MSCs or } \\
\text { BM-MNCs in } \\
\text { each site) }\end{array}$ & 24 weeks & 6 weeks & BM-MSCs & $\begin{array}{l}0.5-1 \mathrm{~mL} \\
\text { BM-MSCs } \\
(20 \text { sites, } \\
3 \mathrm{~cm} \times 3 \mathrm{~cm} \text { in } \\
\text { lengths, } 1-1.5 \mathrm{~cm} \\
\text { in fundus) }\end{array}$ & $\begin{array}{l}\text { Improved: } \\
\text { - The ulcer healing rate } \\
\text { of the BM-MSC group } \\
\text { significantly higher than } \\
\text { that of BM-MNCs } \\
\text { - Painless walking time } \\
\text { - } \mathrm{ABI} \\
\text { - } \mathrm{TCPO}_{2} \\
\text { - Increased collateral } \\
\text { vessels with magnetic } \\
\text { resonance angiography } \\
\text { - Lower limb perfusion } \\
\text { - Ulcer healing } \\
\text { - Blood pressure }\end{array}$ \\
\hline $\begin{array}{l}\text { Jain et al. } \\
\text { [31] } \\
2011 \text {, India }\end{array}$ & $\begin{array}{l}\text { Patients ran- } \\
\text { domized into } \\
25 \text { cases and } \\
23 \text { controls }\end{array}$ & $\begin{array}{l}\text { Borders of the } \\
\text { wound in } 4 \\
\text { distant sites } \\
\text { from the middle } \\
\text { and } 4 \text { additional } \\
\text { intermediate } \\
\text { equal positions } \\
\text { between previ- } \\
\text { ous positions }\end{array}$ & 3 months & 2 weeks & $\begin{array}{l}\text { Autologous } \\
\text { BM-MSC }\end{array}$ & $\begin{array}{l}5 \mathrm{~mL} \text { in } \\
39.6-43.4 \mathrm{~cm}^{2}\end{array}$ & $\begin{array}{l}\text { Improved: } \\
\text { - Wound healing }\end{array}$ \\
\hline $\begin{array}{l}\text { Kirana et al. } \\
{[33]} \\
2012, \\
\text { Germany }\end{array}$ & $\begin{array}{l}\text { Patients were } \\
\text { randomized to } \\
\text { receive either } \\
\text { BM-MNC (12) } \\
\text { or BM-MSC } \\
\text { enriched in } \\
\text { CD } 90^{+} \text {cells (12) }\end{array}$ & $\begin{array}{l}\text { Intramuscular } \\
\text { injection }\end{array}$ & 52 weeks & 16 weeks & $\begin{array}{l}\text { Autologous } \\
\text { BM-MSC }\end{array}$ & $\begin{array}{l}50 \times 10^{6} \text { cells a } \\
3 \mathrm{~cm} \times 5 \mathrm{~cm} \text { area, } \\
4 \mathrm{~cm} \text { deep }\end{array}$ & $\begin{array}{l}\text { Improved: } \\
\text { - Wound healing } 83 \% \\
\text { in the BM-MNC group } \\
\text { and } 80 \% \text { in the BM-MSC } \\
\text { group } \\
\text { - } \mathrm{ABI} \\
\text { - } \mathrm{TcPO}_{2} \\
\text { - Angiogenesis detected } \\
\text { in } 7 \text { of the BM-MSC } \\
\text { group }\end{array}$ \\
\hline
\end{tabular}


Table 1. Continued

\begin{tabular}{|c|c|c|c|c|c|c|c|}
\hline $\begin{array}{l}\text { Reference, } \\
\text { country }\end{array}$ & $\begin{array}{l}\text { Number of } \\
\text { patients }\end{array}$ & $\begin{array}{l}\text { Administration } \\
\text { route }\end{array}$ & $\begin{array}{l}\text { Follow-up } \\
\text { duration }\end{array}$ & $\begin{array}{l}\text { Treatment } \\
\text { duration }\end{array}$ & Cell type & Dosage & Outcome \\
\hline $\begin{array}{l}\text { Wu et al. } \\
\text { [36] } \\
2018 \text {, China }\end{array}$ & $\begin{array}{l}\text { A 54-year-old } \\
\text { woman }\end{array}$ & $\begin{array}{l}\text { Subcutaneous } \\
\text { injection of } \\
\text { BM-MSCs and } \\
\text { autologous } \\
\text { platelet-rich gel }\end{array}$ & $\begin{array}{l}\text { Once } \\
\text { every } \\
5-7 \text { days }\end{array}$ & 30 days & $\begin{array}{l}\text { Autologous } \\
\text { BM-MSCs }\end{array}$ & $\begin{array}{l}\text { Cell: } 2 \times 10^{8} / \mathrm{L} \text { at } \\
2.5 \mathrm{~cm} \times 1.5 \mathrm{~cm}\end{array}$ & $\begin{array}{l}\text { Improved: } \\
\text { - } \mathrm{DFU} \text { healing } \\
\text { - } \mathrm{TCPO}_{2} \\
\text { - } \mathrm{ABI} \\
\text { - } \text { Biochemical evaluation } \\
\text { and multiple tumor } \\
\text { markers were normal }\end{array}$ \\
\hline $\begin{array}{l}\text { Li et al. [37] } \\
\text { 2013, China }\end{array}$ & 15 patients & $\begin{array}{l}\text { Intramuscular } \\
\text { injections }\end{array}$ & 4 weeks & 12 weeks & HUC-MSCs & $\begin{array}{l}10 \mathrm{~mL} \text { (1.6-2.4 } \times \\
10^{6} / \mathrm{mL} 20 \text { sites, } \\
3 \mathrm{~cm} \times 3 \mathrm{~cm} \\
\text { in intervals, } \\
1-1.5 \mathrm{~cm} \text { in- } \\
\text { depth, } 0.5-1 \mathrm{~mL} \\
\text { per site). } \\
2 \mathrm{~mL} \text { was also } \\
\text { delivered into the } \\
\text { basilar portions } \\
\text { of foot ulcers and } \\
\text { the surrounding } \\
\text { subcutaneous } \\
\text { tissues ( } 2 \times 10^{6} \\
\text { cells in each } \\
\text { point) }\end{array}$ & $\begin{array}{l}\text { Improved: } \\
\text { - Skin temperature } \\
\text { - } \mathrm{ABI} \\
\text { - } \mathrm{TcO}_{2} \\
\text { - Wound healing } \\
\text { - Reduction in blood } \\
\text { glucose and insulin } \\
\text { requirement } \\
\text { - Pain, weakness, feeling } \\
\text { coldness, numbness, } \\
\text { and intermittent limp } \\
\text { - Normal blood pressure } \\
\text { and blood lipid profile }\end{array}$ \\
\hline $\begin{array}{l}\text { Qin et al. } \\
\text { [38] } \\
\text { 2013, China }\end{array}$ & $\begin{array}{l}28 \text { cases and } \\
12 \text { controls }\end{array}$ & $\begin{array}{l}\text { Intravenously } \\
\text { injected }\end{array}$ & 3 month & 2 months & HUC-MSCs & $\begin{array}{l}\text { Stem cells } \\
4.8 \times 10^{7} \text { to } \\
8.6 \times 10^{7} \\
\text { Injected into the } \\
\text { diseased limb } \\
\text { from multipoint, } \\
0.5-1.0 \mathrm{~mL} \text { per } \\
\text { point, } \\
3 \mathrm{~cm} \times 3 \mathrm{~cm} \text { area }\end{array}$ & $\begin{array}{l}\text { Improved: } \\
\text { - ABI } \\
\text { - Skin temperature } \\
\text { - Claudication distance } \\
\text { - Number of new vessels } \\
\text { - Success rate of } \\
\text { percutaneous } \\
\text { transluminal } \\
\text { angioplasty was } 82 \% \\
\text { - Success rate for the } \\
\text { treatment of stenosis } \\
\text { was } 88 \% \\
\text { - Success rate for the } \\
\text { treatment of occlusion } \\
\text { was } 59 \%\end{array}$ \\
\hline $\begin{array}{l}\text { Qin et al. } \\
\text { [14] } \\
2016 \text {, China }\end{array}$ & $\begin{array}{l}28 \text { cases and } \\
25 \text { controls }\end{array}$ & $\begin{array}{l}\text { Endovascular } \\
\text { injection and } \\
\text { infusion enci- } \\
\text { rcling the foot } \\
\text { ulcer }\end{array}$ & 2 weeks & $1-3$ months & HUC-MSCs & $\begin{array}{l}4.8 \times 10^{7} \text { to } \\
8.6 \times 10^{7} \text { cells in a } \\
3 \mathrm{~cm} \times 3 \mathrm{~cm} \text { area }\end{array}$ & $\begin{array}{l}\text { Improved: } \\
\text { - Ulcer healing } \\
\text { - } \mathrm{ABI} \\
\text { - } \mathrm{TcPO}_{2} \\
\text { - Skin temperature } \\
\text { - Claudication distance } \\
\text { - New vessels } \\
\text { - Not seen ulcer infection } \\
\text { and sustain normal } \\
\text { blood pressure, and } \\
\text { heart function, blood } \\
\text { glucose, and lipids } \\
\text { - Treatment was not } \\
\text { associated with any } \\
\text { serious complications } \\
\text { or adverse reactions }\end{array}$ \\
\hline
\end{tabular}


Table 1. Continued

\begin{tabular}{|c|c|c|c|c|c|c|c|}
\hline $\begin{array}{l}\text { Reference, } \\
\text { country }\end{array}$ & $\begin{array}{l}\text { Number of } \\
\text { patients }\end{array}$ & $\begin{array}{l}\text { Administration } \\
\text { route }\end{array}$ & $\begin{array}{l}\text { Follow-up } \\
\text { duration }\end{array}$ & $\begin{array}{l}\text { Treatment } \\
\text { duration }\end{array}$ & Cell type & Dosage & Outcome \\
\hline $\begin{array}{l}\text { Han et al. } \\
\text { [39] } \\
\text { 2010, Korea }\end{array}$ & $\begin{array}{l}28 \text { cases and } \\
26 \text { controls } \\
\text { Total } 54 \\
\text { single-blinded }\end{array}$ & $\begin{array}{l}\text { Same-day } \\
\text { procedure. } \\
\text { Dispersed onto } \\
\text { the wound and } \\
\text { sealed with } \\
\text { fibrinogen, } \\
\text { thrombin, and } \\
\text { Tegaderm }\end{array}$ & 8 weeks & $17.3 \pm 8.5$ days & $\begin{array}{l}\text { Through } \\
\text { applying } \\
\text { collagenase } \\
\text { and } \\
\text { centrifugation, } \\
\text { the ADSC pellet } \\
\text { was isolated } \\
\text { (freshly isolated } \\
\text { stem cells) }\end{array}$ & $\begin{array}{l}\text { Autografts } \\
4.0 \times 10^{6} \text { to } \\
8.0 \times 10^{6} \text { cells } \\
\text { Donor site: } \\
\text { abdomen }\end{array}$ & $\begin{array}{l}\text { Improved: } \\
\text { - } 100 \% \text { of wounds in the } \\
\text { case group and } 62 \% \\
\text { in the control group } \\
\text { healed in } 8 \text { weeks, with } \\
\text { no adverse effects }\end{array}$ \\
\hline $\begin{array}{l}\text { Lee et al. } \\
\text { [40] } \\
2012 \text {, Korea }\end{array}$ & $\begin{array}{l}3 \text { diabetic } \\
\text { patients }\end{array}$ & $\begin{array}{l}60 \text { intramuscular } \\
\text { injections under } \\
\text { spinal anesthe- } \\
\text { sia. The interval } \\
\text { between harvest } \\
\text { and injection is } \\
\text { not noted }\end{array}$ & 6 months & 7 days & $\begin{array}{l}\text { Subcutaneous } \\
\text { adipose } \\
\text { used and } \\
\text { digested using } \\
\text { collagenase } \\
\text { and } \\
\text { centrifugation }\end{array}$ & $\begin{array}{l}3 \times 10^{8} \mathrm{ADSC} \\
(0.5 \mathrm{~mL} \text { each, } \\
\text { included } 5 \times 10^{6} \\
\text { in } 60 \text { points })\end{array}$ & $\begin{array}{l}\text { Improved: } \\
\text { - } 100 \% \text { chronic wound } \\
\text { healing } \\
\text { - Pain rating score } \\
\text { - Claudication walking } \\
\text { distances (in } 5 \text { patients) }\end{array}$ \\
\hline $\begin{array}{l}\text { Masłowski } \\
{[41]} \\
2013 \\
\text { Poland }\end{array}$ & 22 cases & - & 6 months & - & ADSC & $5 \mathrm{~mL}$ & $\begin{array}{l}\text { Improved: } \\
\text { - } 8 \text { patients completely } \\
\text { healed } 9 \text { patients } \\
\text { with }>50 \% \text { reduction of } \\
\text { ulcer area } \\
\text { - No improvement in } \\
5 \text { patients }\end{array}$ \\
\hline $\begin{array}{l}\text { Marino et al. } \\
\text { [42] } \\
2013 \text {, Italy }\end{array}$ & 18 patients & $\begin{array}{l}\text { Using a } 10 \mathrm{~mL} \\
\text { syringe with a } 21 \\
\text { gauge needle at } \\
\text { the edges of the } \\
\text { ulcer; cells were } \\
\text { injected at a } \\
\text { depth of } 1 \mathrm{~cm}\end{array}$ & 3 months & 1 day & ADSC & $\begin{array}{l}5 \mathrm{~mL} \\
\left(3 \times 10^{5} \text { cells } / \mathrm{mL}\right)\end{array}$ & $\begin{array}{l}\text { Improved: } \\
\text { - Pain } \\
\text { - } 60 \% \text { healing of the ulcer } \\
\text { patient }\end{array}$ \\
\hline $\begin{array}{l}\text { Moon et al. } \\
\text { [43] } \\
2019 \text {, Korea }\end{array}$ & $\begin{array}{l}30 \text { cases } \\
\text { (ADSC } \\
\text { treatment } \\
\text { group) and } \\
29 \text { controls } \\
\text { (treated with } \\
\text { polyurethane } \\
\text { film) }\end{array}$ & $\begin{array}{l}\text { Applied directly } \\
\text { to the wound } \\
\text { bed }\end{array}$ & 2 years & 12 weeks & $\begin{array}{l}\text { Allogeneic } \\
\text { ADSC }\end{array}$ & $\begin{array}{l}5 \mathrm{~cm} \times 5 \mathrm{~cm} \\
\text { hydrogel sheet } \\
\text { containing allo- } \\
\text { geneic ADSC (the } \\
\text { number of ADSCs } \\
\text { reached about } \\
1 \times 10^{6} \text { cells } / \text { sheet) }\end{array}$ & $\begin{array}{l}\text { Improved: } \\
\text { - Faster complete wound } \\
\text { closure }\end{array}$ \\
\hline $\begin{array}{l}\text { Viswanathan } \\
\text { et al. [44] } \\
2013 \text {, India }\end{array}$ & $\begin{array}{l}5 \text { patients } \\
\text { with PAD and } \\
4 \text { diabetic } \\
\text { ulcers }\end{array}$ & $\begin{array}{l}\text { Intramuscular } \\
\text { approximately } \\
10 \text { separated } \\
\text { sites with } \\
5-8 \mathrm{~cm} \text { space } \\
\text { from each other }\end{array}$ & 14 months & 3 months & $\begin{array}{l}\left(\mathrm{HSCs}, \mathrm{CD} 34^{+}\right) \\
\text {and UC-MSCs } \\
\text { from the HUC } \\
\text { blood }\end{array}$ & $\begin{array}{l}\text { Total calcula- } \\
\text { ted UC-MSCs } \\
\text { and CD } 34^{+} \text {at } 2 \\
\text { million } / \mathrm{kg} \text { body } \\
\text { weight in an } \\
80: 20 \text { ratio } \\
\text { Injection } \\
1-1.5 \mathrm{~mL} \text { was } \\
\text { injected in each } \\
\text { site }\end{array}$ & $\begin{array}{l}\text { Improved: } \\
\text { - Rest pains } \\
\text { - Wound healing } \\
\text { - Ulcer size }\end{array}$ \\
\hline
\end{tabular}


Table 1. Continued

\begin{tabular}{|c|c|c|c|c|c|c|c|}
\hline $\begin{array}{l}\text { Reference, } \\
\text { country }\end{array}$ & $\begin{array}{l}\text { Number of } \\
\text { patients }\end{array}$ & $\begin{array}{l}\text { Administration } \\
\text { route }\end{array}$ & $\begin{array}{l}\text { Follow-up } \\
\text { duration }\end{array}$ & $\begin{array}{l}\text { Treatment } \\
\text { duration }\end{array}$ & Cell type & Dosage & Outcome \\
\hline $\begin{array}{l}\text { Tanaka et al. } \\
\text { [45] } \\
\text { 2014, Japan }\end{array}$ & 5 patients & Intramuscularly & 3 years & $\begin{array}{l}12-26 \text { weeks, } \\
\text { average } \\
18.8 \text { weeks } \\
\text { (131.6 days); } \\
12 \text { weeks post- } \\
\text { therapy, if com- } \\
\text { plete wound } \\
\text { closure did not } \\
\text { occur follow up } \\
\text { continued every } \\
4 \text { weeks }\end{array}$ & $\begin{array}{l}\text { Autologous } \\
\text { G-CSF } \\
\text { mobilized } \\
\text { peripheral } \\
\text { blood CD34+ } \\
\text { cells }\end{array}$ & $\begin{array}{l}2 \times 10^{7} \mathrm{CD}^{+} 4^{+} \\
\text {cells/patient was } \\
\text { administered } \\
20 \text { injections, } \\
\text { each injection } \\
\text { containing } 1 \times \\
10^{6} \text { cells } / 0.25 \mathrm{~mL} \\
\text { saline }(0.25 \mathrm{~mL} \\
\times 20 \text { sites, } \\
1.5-2.0 \mathrm{~cm} \text { deep })\end{array}$ & $\begin{array}{l}\text { Improved: } \\
\text { - Complete wound } \\
\text { closure was observed } \\
\text { for all patients with no } \\
\text { major amputation } \\
\text { - No severe adverse } \\
\text { events occurred during } \\
\text { or after cell therapy }\end{array}$ \\
\hline $\begin{array}{l}\text { Xu and } \\
\text { Liang [46] } \\
\text { 2016, China }\end{array}$ & 127 patients & $\begin{array}{l}\text { Subcutaneous } \\
\text { injections }\end{array}$ & 3 years & $\begin{array}{l}\text { Group } A(\mathrm{n}=63 \text { ), } \\
16,17,16, \text { and } \\
14 \text { patients were } \\
\text { treated for } 4,5 \text {, } \\
6 \text {, and } 7 \text { days, } \\
\text { respectively. } \\
\text { Group B ( } \mathrm{n}= \\
64), 10 \mathrm{mg} / \mathrm{kg} / \\
\text { day Filgras- } \\
\text { tim through } \\
\text { subcutaneous } \\
\text { injections, } 16, \\
17,16, \text { and } 15 \\
\text { patients were } \\
\text { treated for } 4,5 \text {, } \\
6 \text {, and } 7 \text { days, } \\
\text { respectively }\end{array}$ & $\begin{array}{l}\text { Autologous } \\
\text { peripheral } \\
\text { blood stem cell }\end{array}$ & $\begin{array}{l}2 \mathrm{~mL} \text { stem cell } \\
\text { suspension fluid } \\
\text { per marker point }\end{array}$ & $\begin{array}{l}\text { Improved: } \\
\text { - Collateral circulation } \\
\text { - Blood supply to lower } \\
\text { extremities } \\
\text { - Pain in the affected limb } \\
\text { - Cold sense of limbs } \\
\text { - Clinical symptoms } \\
\text { - Healing ulcers } \\
\text { - Quality of life }\end{array}$ \\
\hline
\end{tabular}

$\overline{\mathrm{ABI}}$, ankle-brachial index; $\mathrm{ADSC}$, adipose-derived stem cell; BM-MNC, bone marrow mononuclear cell; BM-MSC, bone marrow mesenchymal stem cell; DFU, diabetic foot ulcer; G-CSF, granulocyte colony-stimulating factor; HSC, hematopoietic stem cell; HUC, human umbilical cord; HUC-MSC, human umbilical cord blood mesenchymal stem cell; $\mathrm{TCPO}_{2}$, transcutaneous oxygen pressure; UC-MSC, umbilical cord-derived mesenchymal stem cell.

did not increase [63]. Adipose-derived stem cell transplantation facilitated the healing of skin ulcers in diabetic mice [64]. In phase I trials, adipose-derived stem cell transplantation could improve percutaneous partial pressure of oxygen in lower extremities and improve treatment of local ulcer in patients with either diabetic or nondiabetic ischemia of the lower limbs [65]. Preliminary experiments using animal models have shown that administering adipose-derived stem cells regulated local angiogenesis by increasing VEGF in plasma and tissue, accelerated wound healing, stimulated neoangiogenesis, and enhanced tissue regeneration via paracrine and autocrine mechanisms [66]. The secretion of several growth factors, including fibroblast growth factor 2, insulin-like growth factor, and hepatocyte growth factor, following administration of adipose-derived stem cells, has a profound effect on wound healing [67]. Moreover, expression of cell surface markers, genes, and differentiation of adipose-derived stem cells into various cells, including keratinocytes, fibroblasts, and endothelial cells, was demonstrated [67].

The use of adipose-derived stem cells for cell-based softtissue engineering and wound healing has been reviewed by Hassan et al. [60]. The application of mesenchymal stem cells by clinicians is very difficult because they are commercially unavailable. In the more recent research by Moon et al. [43], a new commercial hydrogel complex containing adipose-derived stem cells has been evaluated and their study introduced an allogeneic adipose-derived stem cell in a scaffold shield for treating diabetic foot ulcers. A significant difference in the duration of complete wound closure without having adverse effects was observed in the adipose-derived stem cell treated group compared with the control group [43].

Currently, several clinical trials (NCT03370874, NCT02866565, NCT02831075, and NCT02092870) are being conducted on the use of adipose-derived stem cells therapies 
for the treatment of ulcers. However, the number of diabetic patients recovered from adipose-derived stem cells-treated ulcers is small. Some clinical trials are studying the effect of injecting adipose-derived stem cells into the debrided surfaces of chronic ulcers. In ongoing studies (NCT02092870 and NCT02831075), patients will receive treatment with adiposederived stem cells in the form of multiple injections of cells surrounding the wound. The efficacy of using a hydrogel sheet containing allogenic adipose-derived mesenchymal stem cells is being evaluated by another ongoing study (NCT03370874). A study (NCT02866565) has been conducted to investigate the tolerance and efficacy of reinjection of autologous adiposederived stem cells in the treatment of ulcers. Table 1 shows a list of clinical studies using adipose-derived stem cells to treat foot ulcers.

\section{Hematopoietic stem cells}

Hematopoietic stem cells originate in bone marrow, peripheral blood, and cord blood and can be used for allogeneic transplantation [68]. These cells are responsible for sequential lineage commitment to generate all cell types in the blood [69]. Stem cells derived from peripheral blood are faster in engraftment and more beneficial to help survival in advanced diseases than the cells from bone marrow [70]. By contrast, bone marrow collection is conducted in the operating room under general anesthesia. Limited cell concentration and differentiation potential with a performance that will be influenced by comorbidities are observed both in bone marrow and peripheral blood separation, but some disadvantages are only detected in peripheral blood extraction, which include the requirement for administering hematopoietic growth factors administration, and high T-cell content raises the incidence of chronic graft-versus-host disease. However, advantages of hematopoietic stem cells, when prepared from cord blood, include future donor-specific therapy, lower malignancy risk, disposable tissue, umbilical cord tissue harvesting, low surgical risk, and donor umbilical cord blood banking. Low stem cell concentration, limited differentiation potential, increased risk of graft failure, and need for umbilical cord blood banking are considered as disadvantages when the cells are extracted from umbilical cord blood. In addition, ethical conflicts are present in umbilical cord separation and are less present for cells derived from bone marrow or peripheral blood [48].

Possessing over 10 discrete mature cell types in the blood system of mammals relies on hematopoietic stem cells as this is the only distinctive cell type that is capable of multipotency and self-renewal. "Multi-potency is the ability to differentiate into all functional blood cells," and contrasts with self-renewal, "the ability to give rise to the hematopoietic stem cells itself without differentiation." Further, to compensate for the short life-span of the mature blood cells, hematopoietic stem cells attempt to develop into more differentiated progenitors simultaneously while maintaining their pool size by making a precise balance between the self-renewal and differentiation processes [71]. However, such limitations as bone marrow collection, patient's age, stem cell separation and preparation, and variations in the quality and number of cells should be carefully taken into account [44].

Hematopoietic stem cells have a lifelong ability to endure their self-renewal, and differentiation makes them an appropriate tool for gene therapy. Although the properties of hematopoietic stem cells are not explicitly recognized, it has been found that hematopoietic stem cells contain a pool of cells that are capable of reconstituting the hematopoietic system in the long run while expressing the surface glycoprotein CD34 and lacking CD38 (CD34 $\left.{ }^{+} / \mathrm{CD} 38^{-}\right)$[72]. The mechanism of action of $\mathrm{CD} 34^{+}$cell therapy is to mitigate elongated inflammation, increase angiogenesis, and accelerate wound closure, unlike untreated control wounds [73]. Although hematopoietic stem cells mainly produce blood cells, hematopoietic stem cells have been proven to play an essential role in the wound healing process by migrating to cutaneous wounds and regulating cell proliferation $[74,75]$.

The regenerative mechanism of human blood-derived $\mathrm{CD} 34^{+}$cell-induced therapy is facilitated through both vasculogenesis [76] and paracrine mechanisms that stimulate angiogenesis and activate the Wnt signaling pathway in the wound healing process [77]. Similarly, bone marrow-derived hematopoietic stem cells may improve the healing of diabetic ulcers [77].

Unlike vehicle-treated control models, animal models of injury receiving $\mathrm{CD} 34^{+}$had reduced levels of matrix metalloproteinase (MMPs), including MMP1, MMP3, MMP9, and MMP13, in their wound beds [14]. In a study by Chotinantakul et al. [78], the use of expanded cord blood CD $34^{+}$cells or freshly isolated cord blood CD $34^{+}$cells accelerated wound repair through the successful deployment of macrophages and capillaries and re-epithelialization around the wound bed area. As presented in Table 1, hematopoietic stem cells enhance wound healing, reduce ulcers, and enhance the blood supply in the lower extremities of diabetic patients. A study of diabetic patients with end-stage renal disease showed that the application of autologous and purified $\mathrm{CD} 34^{+}$cells to nonhealing chronic wounds increased vascular perfusion and closed the wound completely [45]. Combination treatment with $\mathrm{CD} 34^{+}$cells and umbilical cord blood-derived mesenchymal stem cells was suggested in a preliminary study on 
5 patients [44]. Xu et al. [46] showed that peripheral blood stem cell transplantation could increase the blood supply of the lower extremities in patients with diabetic foot ulcers. It seems that $\mathrm{CD}_{3} 4^{+}$cells are an abundant population of endothelial progenitor cells and are good candidates for cell therapy for ulcers [45].

\section{Embryonic stem cells}

Pluripotency and self-renewal are 2 distinct characteristics of embryonic stem cells. The former refers to the embryonic stem cell capability to give rise to any derivatives of 3 primary germ layers, i.e., endoderm, ectoderm, and mesoderm, while the latter defines embryonic stem cell ability to reproduce without limit under strict conditions [10]. Human embryonic stem cells help the study of early human development, genetic diseases, and performance of in vitro toxicology [79]. These cells are the source of such useful cell types as cardiomyocytes, insulin-secreting cells, dopaminergic neurons, and hematopoietic progenitors. The advantage of these cells is their pluripotency, whereas their increased malignancy risk and potential ethical conflicts are disadvantages [48].

Embryonic stem cells promote the early stage of wound healing by accelerating epithelialization, granulation tissue depth, angiogenesis, and the proliferation of fibroblasts. These are confirmed by the upregulation of cytokines and fibronectin, which are closely related to wound healing $[80,81]$. After the use of embryonic stem cell transplantation in ulcers, Lee et al. [82] found a significant increase in the level of growth factors, specifically epidermal growth factor (EGF), VEGF, and fibronectin. EGF helps to stimulate epithelial cells to grow around the wounds, whereas VEGF increases vascular permeability, deposition of the proangiogenic matrix, and development of blood vessels, and ultimately, fibronectin progresses cell adhesion to the fibrin matrix, where it has a scaffolding role for fresh matrix deposition [83]. Further, embryonic stem cells have immunomodulatory properties [81]. Acellular protein extracts derived from embryonic stem cells have been found to retain some immunoregulatory properties of intact cells [84]. Loretelli et al. [81] found that the extracts could improve ulcer healing in a mouse model of diabetic foot ulcer.

Topical administration of embryonic stem cells can improve diabetic wound healing during the initial stage of the diabetic ulcers [80]. The therapeutic modality of embryonic stem cell transplantation in the treatment of diabetic ulcers was also highlighted. During an investigation of the effect of topical mouse embryonic stem cells on wound healing in a rat model of ulcer, Lee et al. [80] found that immunocompetent rats did not reject embryonic stem cell xenotransplantation and embryonic stem cell application did not induce any tumor formation.

\section{Induced pluripotent stem cells}

Pluripotent stem cells derived from adult somatic cells are induced pluripotent stem cells. These stem cells are reprogrammed into a pluripotent state in vitro by induced expression of 4 transcription factors, including Oct $4 / \mathrm{Sox} 2 / \mathrm{c}-\mathrm{Myc} /$ KLF4 or Oct4/Sox2/NANOG/LIN28 [85]. Induced pluripotent stem cells are an advanced and newly discovered cell type that has potential to further regenerative medicine and drug therapy. Human induced pluripotent stem cells provide a new approach to the treatment of chronic wound healing in preclinical rodent models [85].

The administration of induced pluripotent stem cells is advantageous in several ways, including pluripotency, targeted somatic-cell memory, donor-specificity, relative absence of ethical conflicts, tissue disposability, and low cell harvesting risk [48]. The specific potential of induced pluripotent stem cells is that they can develop into various required cells. Induced pluripotent stem cells have the advantages of differentiate into various tissues and cell types in vitro resulting in the generation of new cell types, as do embryonic stem cells in utero during embryonic development $[86,87]$, while the disadvantages of induced pluripotent stem cells include increased malignancy risk, complex induction protocol, and biased somatic-cell memory [48].

Due to the ability of these cells to differentiate into any of the 3 germ cell layers, induced pluripotent stem cells are a potential source for promoting each phase of diabetic wound healing by using their paracrine and direct cellular properties [88]. During the inflammatory phase, growth factors and cytokines are secreted by cells derived from induced pluripotent stem cells [89]. Furthermore, induced pluripotent stem cells induce an increase in the number of macrophages [90]. In a proliferative phase, angiogenesis is promoted by induced pluripotent stem cell-derived cells, including endothelial cells, smooth muscle cells, fibroblasts, pericytes, keratinocytes, and mesenchymal stem cells, while there is increased deposition of collagen simultaneously [90]. Unlike mesenchymal stem cells, induced pluripotent stem cells can differentiate into keratinocytes [91].

Induced pluripotent stem cell-derived fibroblasts potentiate a repair-progression phenotype and improved mitochondrial function when compared with fibroblasts from which they were initially reprogrammed [92]. However, whether diabetic foot ulcer-derived induced pluripotent stem cells could be 
differentiated into mesenchymal fibroblasts that may perhaps have a biological function that may improve healing when they are used therapeutically for diabetic foot ulcer remains unknown.

\section{Uncommon stem cells}

There are also some uncommon types of cells used to treat diabetic foot ulcers. According to Kim et al. [64], the process of wound healing was better enhanced through intradermal injections of human amniotic mesenchymal stem cells than human adipose-derived stem cells or human dermal fibroblasts in a murine model of ulcers. Similarly, Zheng et al. [93] indicated that the topical administration of micronized amniotic membrane containing human amniotic epithelial cells could improve ulcer repair in diabetic mice compared with the application of decellularized membrane. Lv et al. [94] found a similar healing effect of stem cells derived from the human exfoliated deciduous tooth and human bone marrow mesenchymal stem cells transplanted into a rat model of DM. Kong et al. [22] found enhanced wound healing in diabetic Goto-Kakizaki rats by intradermal injection of human placental mesenchymal stem cells. Badillo et al. [95] showed that the injection of mesenchymal stem cell-containing collagen gel that is derived from embryonic, fetal liver stem cells, to diabetic Lepr ${ }^{\mathrm{db} / \mathrm{db}}$ mice, led to improved wound healing. By contrast, $\mathrm{CD}_{4} 5^{+}$cell transplants did not produce the same effect. To promote human fetal aortic mesenchymal stem cells for wound healing, Barcelos et al. [77] administered a collagen hydrogel scaffold in a murine model of ischemic diabetic ulcer. Finally, the therapeutic efficacy of primary adult stem cell transplantation to manage nonhealing diabetic ulcers should not be overlooked [93].

\section{Routes of administration}

Transplantation of stem cells in diabetic foot ulcers is affected by either local or systematic strategies. Presently, nonvascular injections into tissue are the most commonly used route of administration of stem cells to treat ulcers. Stem cells are administered as either direct injection into the ulcer or local site. Preclinical studies primarily adhere to intradermal and subcutaneous routes, whereas clinical trials mainly use an intramuscular approach to administer cells [48]. The other standard local route is topical administration, such as the use of sprays, drops, and scaffolds [96]. Although these local routes are beneficial and less hazardous, they are associated with significant cell mortality and poor engraftment that require debridement to decrease the infection risk. Kwon et al. [97] showed that a single local administration of allogeneic bone marrow-mesenchymal stem cells increased wound strength in rats with ulcers. By contrast, multiple intravenous injections did not produce any significant increase in the wound strength, indicating the efficacy of local injection.

Although both intra-arterial and intravenous injections were helpful in the delivery of endovascular stem cells, they cannot guarantee the successful access of the infused stem cells to the site of the ulcer. These injection methods have had an optimal effect on immunomodulation and glucose homeostasis [98]. Nonetheless, we should bear in mind that a clinical study showed that 2 of 33 diabetic patients with severe limb ischemia, who received autologous adipose-derived stem cells by intra-arterial infusion, presented peripheral microthrombosis [99]. Furthermore, systematic is more expensive than local administration.

\section{Safety and efficacy}

Intramuscular transplantation of bone marrow mesenchymal stem cells has been found to be safe and effective [28]. In more recent years, more effective and safe results have been obtained for the treatment of diabetic foot ulcers using bone marrow mesenchymal stem cell transplantation. However, achieving full interpretation of results from research has been challenged by the variability of stem cell types and origins along with the diversity of administration routes and protocols, and the use of angioplasty [48].

Safety is a matter of concern in all cell therapies. To achieve complete safety, the process of generating safe cell derivatives should be meticulously monitored to ensure that not only do the derived cells possess an overall phenotype and functionality, but also that the cultured cells maintain their untransformed state and remain microbiologically uncontaminated. Thus, an efficient quality control management system is essentially required to supervise the procedure of mesenchymal stem cell banking and cell product manufacturing to assure the ultimate safety and efficacy of final cell products [100]. Furthermore, the employment of biologists per se would not suffice for the production of mesenchymal stem cells, implying the necessity of cell engineering technologies to be developed further so that the technologies can be used for large-scale cell product manufacturing in cell factories rather than primitive mesenchymal stem cell generation in laboratories [100]. Clinical trials have found that the autologous transplantation of bone marrow mesenchymal stem cells had a significant impact on maintaining the functional state of the liver and kidneys and subsequently resulted in reduced wound 
size and increased painless walking ability following interventions [20]. In clinical trials, autologous transplantation of bone marrow mesenchymal stem cells can significantly improve clinical parameters, including a decrease in wound size and an increase in pain-free walking distance, while maintaining normal renal and liver function following the intervention [25]. Leg perfusion is also adequately improved to reduce the incidence of major amputations [6]. After 6 weeks of intervention, an intramuscular injection of autologous bone marrow mesenchymal stem cells can significantly increase the rate of ulcer cure in patients with DM. Further significant improvements in painless walking time, limb perfusion, ankle-brachial index, transcutaneous oxygen pressure, and magnetic resonance angiography were observed within 24 weeks of followup [34].

It should be noted that despite the substantial advantages provided by adipose-derived stem cells in regenerative medicine, numerous safety concerns such as the risk of malignant transformation and cancer induction have been discussed. Rubio et al. [101] reported a spontaneous transformation of stem cells into malignant phenotypes. However, they retracted their article due to the inability to replicate the transformation events and a suspicion of contamination [102]. All clinical research conducted to date confirmed the safety of adiposederived stem cells treatment in patients with an ulcer. Albeit, these studies are limited by their small sample size and short follow-up period. Therefore, further attention is needed to evaluate the long-term safety of adipose-derived stem cellsderived therapeutics [39, 40-43, 65, 99].

By contrast, adipose-derived stem cells can promote diabetic wound healing by increasing the rate of epithelialization and granulation tissue formation, anti-inflammatory, and anti-apoptotic effects, and release of angiogenic cytokines. Moreover, a few small clinical trials found that adiposederived stem cells treatment in patients with ulcer caused enhanced ulcer healing, lowered pain scores, and improved absolute claudication distance with no reported complications [39, 40-43, 65]. Li et al. [37] showed that the injection of allogeneic umbilical cord blood-derived mesenchymal stem cells into the quadriceps muscles of ulcer patients was associated with improved clinical outcomes. They reported a decrease in the levels of blood glucose, insulin dosage, c-reactive protein, and tumor necrosis factor- $\alpha$, and an increase in the level of VEGF. The application of umbilical cord blood-derived mesenchymal stem cells also led to gradual improvements in the faintness, numbness, discomfort, cold feeling, intermittent limp, fever, ankle-brachial index, and transcutaneous oxygen pressure in patients with diabetes [37]. However, a phase I study on patients with limb ischemia indicated that intramuscular injection of allogeneic umbilical cord blood-derived mesenchymal stem cells was associated with some side effects. Adverse events, including oral ulceration, whole-body urticaria, diarrhea, and elevation of serum creatinine level, were observed in 3 patients; interestingly, the events were resolved in a short time in all of the patients [103]. However, so far, the use of umbilical cord bloodderived mesenchymal stem cells for the treatment of ulcers has been limited. We consider that the extraction of umbilical cord blood-derived mesenchymal stem cells involves privacy and ethical concerns; also, the cost of preserving umbilical cord blood is very high. Consequently, we recommend prospective investigators to conduct further studies to address these controversial issues and ensure the practicality of stem cell therapies in clinical settings.

\section{Future perspectives}

Stem cell transplantation therapy for diabetic foot ulcer has the potential to improve healing outcomes for patients with diabetes. However, most studies of the therapy have been conducted using animal models of the disease, with few human studies to corroborate the findings. Given the tremendous therapeutic potential inherent in stem cell transplantation therapy for an otherwise chronic condition such as an ulcer with high morbidity, more clinical trials in human subjects are warranted to demonstrate its safety, efficacy, and tolerance.

Although autologous stem cells are the most commonly used cell type used for treatment, future studies to explore the use of induced pluripotent stem cell and allogeneic or xenogenic cells are warranted. Administration of granulocyte colony-stimulating factor promotes wound healing, and its use is recommended as an adjunct to peripheral blood mesenchymal stem cells therapy [46]. Hydrogels and bioscaffolds are promising topical delivery vehicles, but the impact of matrix design and configuration on stem cell function remains unknown [43, 96]. Angioplasty is a promising adjuvant to stem cell therapy in patients needing revascularization, and whether stem cell therapy will be used as an adjuvant to angioplasty remains to be determined [14].

With the improvement in stem cell delivery vehicles and larger-scale clinical trials of stem cell therapy in humans, this promising therapeutic modality for patients with foot ulcer should fulfill its potential.

\section{Limitations}

Concern about the quantity and quality of stem cells is an essential limitation of stem cell transplantation therapy [85]. 
The low rate of cell survival in vivo seen with many stem cell approaches has been a significant limitation in wound healing. Most topical remedies tested do not have any impact on impaired vasculature that contributes to impair healing of diabetic foot ulcers [104]. In addition to cell survival in vivo, limitations of stem cell transplantation therapy include ethical issues associated with the use of some stem cells derived from embryos and umbilical cord blood, teratogenic potential, need for invasive harvesting techniques for bone marrow-derived cells, and immunogenicity.

Moreover, stem cell sources, the number of delivered cells, and cell administration routes differ between the various studies. Due to these heterogeneities, optimized protocols have not yet been determined.

\section{Conclusions}

There exist various sources of stem cells for transplantation to enhance angiogenesis in ischemic regions. Stem cell transplantation is an innovative technology, but its use to treat diabetic foot ulcers is controversial in the field of diabetic angiopathies.

Author contributions. SSH and RM contributed to the conception of the work. SSH, MH, SS, EA, and RM contributed to the design of the work. SSH, SS, EA, HS, and SD performed the literature search and data analysis. SSH, MH, SS, EA, HS, $\mathrm{SD}$, and RM contributed to drafting the work. SSH, MH, SS, EA, and RM contributed to revising the work. All authors have approved the final version submitted for publication and take responsibility for the statements made in the published article.

Acknowledgments. The authors thank the Iran National Science Foundation for their support of our project "Investigation of the therapeutic potential of fibroblast and adiposederived mesenchymal stem cells loaded on nanofiber scaffolds for healing the diabetic foot ulcer in diabetic patients and comparison with common procedures" (retrospective) clinical trial registration number (IRCTID): IRCT20190214042712N1 and the present review article. Elham Amini is presently a postdoctoral student in the Department of Biology, Faculty of Biological Sciences and Technologies, University of Isfahan, Isfahan 81746-73441, Iran.

Conflicts of interest. All the authors have completed and submitted an International Committee of Medical Journal Editors Uniform Disclosure Form for Potential Conflicts of Interest. None of the authors has any potential or actual conflict of interest to disclose in relation to the published article.
Data sharing statement. No data sets were generated or analyzed during the present study. The present review was based on the references cited.

\section{References}

[1] Noor S, Zubair M, Ahmad J. Diabetic foot ulcer-a review on pathophysiology, classification and microbial etiology. Diabetes Metab Syndr. 2015; 9:192-9.

[2] Arshad M, Arshad S, Arshad S, Abbas H. The quality of life in patients with diabetic foot ulcers. J Diab Metab. 2020; 11:e101. doi: 10.35248/2155-6156.20.11.e101.

[3] Haghdoost A, Rezazadeh Kermani M, Sadghirad B, Baradaran H. Prevalence of type 2 diabetes in the Islamic Republic of Iran: systematic review and meta-analysis. Eastern Mediterr Health J. 2009: 15:591-9.

[4] Shafiee S, Raz A, Adibi N, Mansouri M, Annabestani Z, Mirzaeezadeh $Z$, et al. Assessment of the relationship between $-1562 \mathrm{C}>\mathrm{T}$ allele of MMP9 gene promoter with diabetic foot ulcer in type 2 diabetic patients referred to the clinic of diabetes \& metabolic diseases. Iranian J Diabetes Metabol. 2018; 17:49-56. [in Persian; English title and abstract]

[5] Weledji EP, Fokam P. Treatment of the diabetic foot - to amputate or not? BMC Surg. 2014; 14:83. doi: 10.1186/1471-2482-14-83

[6] Cao Y, Gang X, Sun C, Wang G. Mesenchymal stem cells improve healing of diabetic foot ulcer. J Diabetes Res. 2017; 2017:9328347. doi: $10.1155 / 2017 / 9328347$

[7] Guo J, Dardik A, Fang K, Huang R, Gu Y. Meta-analysis on the treatment of diabetic foot ulcers with autologous stem cells. Stem Cell Res Ther. 2017; 8:228. doi: 10.1186/s13287-017-0683-2

[8] Shu X, Shu S, Tang S, Yang L, Liu D, Li K, et al. Efficiency of stem cell based therapy in the treatment of diabetic foot ulcer: a meta-analysis. Endocr J. 2018; 65:403-13.

[9] Heublein H, Bader A, Giri S. Preclinical and clinical evidence for stem cell therapies as treatment for diabetic wounds. Drug Discov Today. 2015; 20:703-17.

[10] Meamar R, Nasr-Esfahani MH, Mousavi SA, Basiri K. Stem cell therapy in amyotrophic lateral sclerosis. J Clin Neurosci. 2013; 20:1659-63.

[11] Blumberg SN, Berger A, Hwang L, Pastar I, Warren SM, Chen W. The role of stem cells in the treatment of diabetic foot ulcers. Diabetes Res Clin Pract. 2012; 96:1-9.

[12] Ariyanti AD, Zhang J, Marcelina O, Nugrahaningrum DA, Wang G, Kasim V, Wu S. Salidroside-pretreated mesenchymal stem cells enhance diabetic wound healing by promoting paracrine function and survival of mesenchymal stem cells under hyperglycemia. Stem Cells Transl Med. 2019; 8:404-14.

[13] Holm JS, Toyserkani NM, Sorensen JA. Adipose-derived stem cells for treatment of chronic ulcers: current status. Stem Cell Res Ther. 2018; 9:142. doi: 10.1186/s13287-018-0887-0

[14] Qin HL, Zhu XH, Zhang B, Zhou L, Wang WY. Clinical evaluation of human umbilical cord mesenchymal stem cell transplantation after angioplasty for diabetic foot. Exp Clin Endocrinol Diabetes. 2016; 124:497-503.

[15] Davey GC, Patil SB, O'Loughlin A, O’Brien T. Mesenchymal stem cell-based treatment for microvascular and secondary complications of diabetes mellitus. Front Endocrinol (Lausanne). 2014; 5:86. doi: $10.3389 /$ fendo.2014.00086 
[16] Ivanova NB, Dimos JT, Schaniel C, Hackney JA, Moore KA, Lemischka IR. A stem cell molecular signature. Science. 2002; 298(5593):601-4.

[17] Arwert EN, Hoste E, Watt FM. Epithelial stem cells, wound healing and cancer. Nature Rev Cancer. 2012; 12:170-80.

[18] Li Z, Hu X, Zhong JF. Mesenchymal stem cells: characteristics, function, and application. Stem Cells Int. 2019; 2019:8106818. doi: $10.1155 / 2019 / 8106818$

[19] Banijamali RS, Soleimanjahi H, Soudi S, Karimi H, Abdoli A, Khorrami SMS, Zandi K. Kinetics of oncolytic reovirus T3D replication and growth pattern in mesenchymal stem cells. Cell J. 2020; 22:283-92.

[20] Dash NR, Dash SN, Routray P, Mohapatra S, Mohapatra PC. Targeting nonhealing ulcers of lower extremity in human through autologous bone marrow-derived mesenchymal stem cells. Rejuvenation Res. 2009; 12:359-66.

[21] Patel AN, Bartlett CE, Ichim TE. Mesenchymal Stem Cells. In: Perin EC, Miller LW, Taylor D, Willerson JT, editors. Stem cell and gene therapy for cardiovascular disease. Amsterdam: Elsevier Academic Press; 2016, p. 139-50.

[22] Kong P, Xie X, Li F, Liu Y, Lu Y. Placenta mesenchymal stem cell accelerates wound healing by enhancing angiogenesis in diabetic Goto-Kakizaki (GK) rats. Biochem Biophys Res Commun. 2013; 438:410-9.

[23] Wang Y, Dan Q, Wang Q, Zhou N, Jin X, Hou Z, et al. [Human umbilic mesenchymal stromal cells repairs diabetic foot in rats associated with VEGF expressional change]. Sichuan Da Xue Xue Bao Yi Xue Ban [J Sichuan Univ. Med Sci Edition]. 2014; 45:29-33. [article in Chinese, English Abstract]

[24] Son W-S, Park HJ, Lee C-J, Kim S-N, Song SU, Park G, Lee Y-W. Supercritical drying of vascular endothelial growth factor in mesenchymal stem cells culture fluids. J Supercritical Fluids. 2020; 157:104710. doi: 10.1016/j.supflu.2019.104710

[25] Shen L, Zeng W, Wu Y-X, Hou C-L, Chen W, Yang M-C, et al. Neurotrophin-3 accelerates wound healing in diabetic mice by promoting a paracrine response in mesenchymal stem cells. Cell Transplant. 2013; 22:1011-21.

[26] Tsyb A, Petrov V, Konoplyannikov A, Saypina E, Lepechina L, Kalsina SS, et al. In vitro inhibitory effect of mesenchymal stem cells on zymosan-induced production of reactive oxygen species. Bull Exp Biol Med. 2008; 146:158-64.

[27] Pan G, Mu Y, Hou L, Liu J. Examining the therapeutic potential of various stem cell sources for differentiation into insulin-producing cells to treat diabetes. Ann Endocrinol (Paris). 2019; 80:47-53.

[28] Wan J, Xia L, Liang W, Liu Y, Cai Q. Transplantation of bone marrow-derived mesenchymal stem cells promotes delayed wound healing in diabetic rats. J Diabetes Res. 2013; 2013:647107. doi: 10.1155/2013/647107

[29] Wang L, Wang F, Zhao L, Yang W, Wan X, Yue C, Mo Z. Mesenchymal stem cells coated by the extracellular matrix promote wound healing in diabetic rats. Stem Cells Int. 2019; 2019:9564869. doi: 10.1155/2019/9564869. [Erratum: doi: 10.1155/2019/9581478]

[30] Debin L, Youzhao J, Ziwen L, Xiaoyan L, Zhonghui Z, Bing C. Autologous transplantation of bone marrow mesenchymal stem cells on diabetic patients with lower limb ischemia. J Med Colleges PLA. 2008; 23:106-15.

[31] Jain P, Perakath B, Ranjan Jesudason M, Nayak S. The effect of autologous bone marrow-derived cells on healing chronic lower extremity wounds: results of a randomized controlled study. Ostomy Wound Manage. 2011; 57:38-34.

[32] Liu Z, Yu D, Xu J, Li X, Wang X, He Z, Zhao T. Human umbilical cord mesenchymal stem cells improve irradiation-induced skin ulcers healing of rat models. Biomed Pharmacother. 2018; 101:729-36.

[33] Kirana S, Stratmann B, Prante C, Prohaska W, Koerperich H, Lammers D, et al. Autologous stem cell therapy in the treatment of limb ischaemia induced chronic tissue ulcers of diabetic foot patients. Int J Clin Pract. 2012; 66:384-93.

[34] Lu D, Chen B, Liang Z, Deng W, Jiang Y, Li S, et al. Comparison of bone marrow mesenchymal stem cells with bone marrow-derived mononuclear cells for treatment of diabetic critical limb ischemia and foot ulcer: a double-blind, randomized, controlled trial. Diabetes Res Clin Pract. 2011; 92:26-36.

[35] Vojtaššák J, Danišovič L, Kubeš M, Bakoš D, Jarabek L, Uličná M, Blaško M. Autologous biograft and mesenchymal stem cells in treatment of the diabetic foot. Neuroendocrinol Lett. 2006; 27(Suppl 2):134-7.

[36] Wu Q, Lei X, Chen L, Zheng Y, Huang H, Qian C, Liang Z. Autologous platelet-rich gel combined with in vitro amplification of bone marrow mesenchymal stem cell transplantation to treat the diabetic foot ulcer: a case report. Ann Transl Med. 2018; 6:307. doi: $10.21037 / \mathrm{atm} .2018 .07 .12$

[37] Li X-Y, Zheng Z-H, Li X-Y, Guo J, Zhang Y, Li H, et al. Treatment of foot disease in patients with type 2 diabetes mellitus using human umbilical cord blood mesenchymal stem cells: response and correction of immunological anomalies. Curr Pharm Des. 2013; 19:4893-9.

[38] Qin H-L, He K-W, Bin G, Ji Y-L, Huang Y-C, Wang S-Q, et al. Human umbilical cord mesenchymal stem cell transplantation combined with angioplasty for diabetic foot: 3 months angiographic evaluation. Zhongguo Zuzhi Gongcheng Yanjiu [Chinese J Tissue Eng Res]. 2013; 17:2544-51.

[39] Han S-K, Kim H-R, Kim W-K. The treatment of diabetic foot ulcers with uncultured, processed lipoaspirate cells: a pilot study. Wound Repair Regen. 2010; 18:342-8.

[40] Lee HC, An SG, Lee HW, Park J-S, Cha KS, Hong TJ, et al. Safety and effect of adipose tissue-derived stem cell implantation in patients with critical limb ischemia: a pilot study. Circ J. 2012; 76:1750-60.

[41] Masłowski L, Paprocka M, Czyżewska-Buczyńska A, Bielawska-Pohl A, Duś D, Grendziak R, et al. Autotransplantation of the adipose tissue-derived mesenchymal stem cells in therapy of venous stasis ulcers. Arch Immunol Ther Exp (Warsz). 2020; 68:5. doi: 10.1007/s00005-020-00571-9

[42] Marino G, Moraci M, Armenia E, Orabona C, Sergio R, De Sena $\mathrm{G}$, et al. Therapy with autologous adipose-derived regenerative cells for the care of chronic ulcer of lower limbs in patients with peripheral arterial disease. J Surg Res. 2013; 185:36-44.

[43] Moon K-C, Suh H-S, Kim K-B, Han S-K, Young K-W, Lee J-W, Kim M-H. Potential of allogeneic adipose-derived stem cellhydrogel complex for treating diabetic foot ulcers. Diabetes. 2019; 68:837-46.

[44] Viswanathan C, Shetty P, Sarang S, Cooper K, Ghosh D, Bal A. Role of combination cell therapy in non-healing diabetic ulcers in patients with severe peripheral arterial disease - a preliminary report on five cases. J Diabetic Foot Complications. 2013; 5:1-14. 
[45] Tanaka R, Masuda H, Kato S, Imagawa K, Kanabuchi K, Nakashioya C, et al. Autologous G-CSF-mobilized peripheral blood $\mathrm{CD} 34^{+}$cell therapy for diabetic patients with chronic nonhealing ulcer. Cell Transplant. 2014; 23:167-79.

[46] Xu SM, Liang T. Clinical observation of the application of autologous peripheral blood stem cell transplantation for the treatment of diabetic foot gangrene. Exp Ther Med. 2016; 11:283-8.

[47] Stiner R, Alexander M, Liu G, Liao W, Liu Y, Yu J, et al. Transplantation of stem cells from umbilical cord blood as therapy for type I diabetes. Cell Tissue Res. 2019; 378:155-62.

[48] Lopes L, Setia O, Aurshina A, Liu S, Hu H, Isaji T, et al. Stem cell therapy for diabetic foot ulcers: a review of preclinical and clinical research. Stem Cell Res Ther. 2018; 9:188. doi: 10.1186/s13287-0180938-6

[49] Abdal Dayem A, Lee SB, Kim K, Lim KM, Jeon T-I, Seok J, Cho S-G. Production of mesenchymal stem cells through stem cell reprogramming. Int J Mol Sci. 2019; 20:1922. doi: 10.3390/ ijms 20081922

[50] Lau T, Lam F, Lau K, Chan Y, Lee K, Sahota D, et al. Pharmacological investigation on the wound healing effects of Radix Rehmanniae in an animal model of diabetic foot ulcer. J Ethnopharmacol. 2009; 123:155-62.

[51] Watt SM, Gullo F, van der Garde M, Markeson D, Camicia R, Khoo $\mathrm{CP}$, Zwaginga JJ. The angiogenic properties of mesenchymal stem/ stromal cells and their therapeutic potential. Br Med Bull. 2013; 108:25-53.

[52] Zhao Q-S, Xia N, Zhao N, Li M, Bi C-L, Zhu Q, et al. Localization of human mesenchymal stem cells from umbilical cord blood and their role in repair of diabetic foot ulcers in rats. Int J Biol Sci. 2014; 10:80-9.

[53] Zhou N, Wang Q-P, Jin X-F, Hou Z-L, Peng B-K, Dan Q-Q, Wang T-H. [Effect of human umbilici mesenchymal stromal cells implantation on the BDNF expression in diabetic foot rats]. Sichuan Da Xue Xue Bao Yi Xue Ban [J Sichuan Univ. Med Sci Edition]. 2013; 44:931-4. [article in Chinese, English Abstract]

[54] You H-J, Namgoong S, Han S-K, Jeong S-H, Dhong E-S, Kim W-K. Wound-healing potential of human umbilical cord blood-derived mesenchymal stromal cells in vitro-a pilot study. Cytotherapy. 2015; 17:1506-13.

[55] Qin H-L, He K-W, Gao B, Ji Y-L, Huang Y-C, Wang S-Q, et al. Human umbilical cord mesenchymal stem cell transplantation combined with angioplasty for diabetic foot: 3 months angiographic evaluation. Chinese J Tissue Eng Res. 2013; 17:2544-51.

[56] Zuk PA, Zhu M, Ashjian P, De Ugarte DA, Huang JI, Mizuno H, et al. Human adipose tissue is a source of multipotent stem cells. Mol Biol Cell. 2002; 13:4279-95.

[57] Wu Q, Chen B, Liang Z. Mesenchymal stem cells as a prospective therapy for the diabetic foot. Stem Cells Int. 2016; 2016:4612167. doi: $10.1155 / 2016 / 4612167$

[58] Nambu M, Ishihara M, Kishimoto S, Yanagibayashi S, Yamamoto $\mathrm{N}$, Azuma R, et al. Stimulatory effect of autologous adipose tissue-derived stromal cells in an atelocollagen matrix on wound healing in diabetic $d b / d b$ mice. J Tissue Eng. 2011; 2011:158105. doi: 10.4061/2011/158105

[59] Yang M, Sheng L, Zhang TR, Li Q. Stem cell therapy for lower extremity diabetic ulcers: where do we stand? Biomed Res Int. 2013; 2013:462179. doi: 10.1155/2013/462179
[60] Hassan WU, Greiser U, Wang W. Role of adipose-derived stem cells in wound healing. Wound Repair Regen. 2014; 22:313-25.

[61] Kim YJ, Kim HK, Cho HH, Bae YC, Suh KT, Jung JS. Direct comparison of human mesenchymal stem cells derived from adipose tissues and bone marrow in mediating neovascularization in response to vascular ischemia. Cell Physiol Biochem. 2007; 20:867-76.

[62] Ikegame Y, Yamashita K, Hayashi S-I, Mizuno H, Tawada M, You F, et al. Comparison of mesenchymal stem cells from adipose tissue and bone marrow for ischemic stroke therapy. Cytotherapy. 2011; 13:675-85.

[63] Jiang X-Y, Lu D-B, Chen B. Progress in stem cell therapy for the diabetic foot. Diabetes Res Clin Pract. 2012; 97:43-50.

[64] Kim S-W, Zhang H-Z, Guo L, Kim J-M, Kim MH. Amniotic mesenchymal stem cells enhance wound healing in diabetic NOD/ SCID mice through high angiogenic and engraftment capabilities. PLoS One. 2012; 7:e41105. doi: 10.1371/journal.pone.0041105

[65] Bura A, Planat-Benard V, Bourin P, Silvestre J-S, Gross F, Grolleau J-L, et al. Phase I trial: the use of autologous cultured adiposederived stroma/stem cells to treat patients with non-revascularizable critical limb ischemia. Cytotherapy. 2014; 16:245-57.

[66] Kato Y, Iwata T, Washio K, Yoshida T, Kuroda H, Morikawa S, et al. Creation and transplantation of an adipose-derived stem cell (ASC) sheet in a diabetic wound-healing model. J Vis Exp. 2017:e54539. doi: 10.3791/54539

[67] Shingyochi Y, Orbay H, Mizuno H. Adipose-derived stem cells for wound repair and regeneration. Expert Opin Biol Ther. 2015; 15:1285-92.

[68] Ito K, Bonora M, Ito K. Metabolism as master of hematopoietic stem cell fate. Int J Hematol. 2019; 109:18-27.

[69] Huo Y, Li B-Y, Lin Z-F, Wang W, Jiang X-X, Chen X, et al. MYSM1 is essential for maintaining hematopoietic stem cell (HSC) quiescence and survival. Med Sci Monit. 2018; 24:2541-9.

[70] Haspel RL, Miller KB. Hematopoietic stem cells: source matters. Curr Stem Cell Res Ther. 2008; 3:229-36.

[71] Seita J, Weissman IL. Hematopoietic stem cell: self-renewal versus differentiation. Wiley Interdiscip Rev Syst Biol Med. 2010; 2:640-53.

[72] Hossle JP, Seger RA, Steinhoff D. Gene therapy of hematopoietic stem cells: strategies for improvement. News Physiol Sci. 2002; 17:87-92.

[73] Kanji S, Das M, Aggarwal R, Lu J, Joseph M, Pompili VJ, Das H. Nanofiber-expanded human umbilical cord blood-derived CD $34^{+}$ cell therapy accelerates cutaneous wound closure in NOD/SCID mice. J Cell Mol Med. 2014; 18:685-97.

[74] Körbling M, Katz RL, Khanna A, Ruifrok AC, Rondon G, Albitar $\mathrm{M}$, et al. Hepatocytes and epithelial cells of donor origin in recipients of peripheral-blood stem cells. N Engl J Med. 2002; 346:738-46.

[75] Kirby GTS, Mills SJ, Cowin AJ, Smith LE. Stem cells for cutaneous wound healing. Biomed Res Int. 2015; 2015:285869. doi: $10.1155 / 2015 / 285869$

[76] Sietsema WK, Kawamoto A, Takagi H, Losordo DW. Autologous CD34+ cell therapy for ischemic tissue repair. Circ J. 2019; 83:1422-30.

[77] Barcelos LS, Duplaa C, Kränkel N, Graiani G, Invernici G, Katare $\mathrm{R}$, et al. Human $\mathrm{CD}_{133^{+}}$progenitor cells promote the healing of diabetic ischemic ulcers by paracrine stimulation of angiogenesis and activation of Wnt signaling. Circ Res. 2009; 104:1095-102. 
[78] Chotinantakul K, Dechsukhum C, Dejjuy D, Leeanansaksiri $\mathrm{W}$. Enhancement of wound closure in diabetic mice by ex vivo expanded cord blood CD $34^{+}$cells. Cell Mol Biol Lett. 2013; 18:263-83.

[79] Lewis P, Silajdžić E, Brison DR, Kimber SJ. Embryonic stem cells. In: Gimble JM, Marolt Preson D, Oreffo R, Wolbank S, Redl H, editors. Cell engineering and regeneration. Redl $\mathrm{H}$, series editor. Reference Series in Biomedical Engineering. Cham: Springer Nature Switzerland; 2020, p. 315-65.

[80] Lee KB, Choi J, Cho S-B, Chung J-Y, Moon E-S, Kim N-S, Han H-J. Topical embryonic stem cells enhance wound healing in diabetic rats. J Orthop Res. 2011; 29:1554-62.

[81] Loretelli C, Nasr MB, Giatsidis G, Bassi R, Lancerotto L, D’Addio $\mathrm{F}$, et al. Embryonic stem cell extracts improve wound healing in diabetic mice. Acta Diabetol. 2020: 57:883-90.

[82] Lee MJ, Kim J, Lee KI, Shin JM, Chae JI, Chung HM. Enhancement of wound healing by secretory factors of endothelial precursor cells derived from human embryonic stem cells. Cytotherapy. 2011; 13:165-78.

[83] Clark RAF, Lanigan JM, DellaPelle P, Manseau E, Dvorak HF, Colvin RB. Fibronectin and fibrin provide a provisional matrix for epidermal cell migration during wound reepithelialization. J Invest Dermatol. 1982; 79:264-9.

[84] Mohib K, Allan D, Wang L. Human embryonic stem cell-extracts inhibit the differentiation and function of monocyte-derived dendritic cells. Stem Cell Rev Rep. 2010; 6:611-21.

[85] Gorecka J, Kostiuk V, Fereydooni A, Gonzalez L, Luo J, Dash B, et al. The potential and limitations of induced pluripotent stem cells to achieve wound healing. Stem Cell Res Ther. 2019; 10:87. doi: 10.1186/s13287-019-1185-1

[86] Bian X, Ma K, Zhang C, Fu X. Therapeutic angiogenesis using stem cell-derived extracellular vesicles: an emerging approach for treatment of ischemic diseases. Stem Cell Res Ther. 2019; 10:158. doi: 10.1186/s13287-019-1276-z

[87] Yoshida Y, Yamanaka S. Recent stem cell advances: induced pluripotent stem cells for disease modeling and stem cell-based regeneration. Circulation. 2010; 122:80-7.

[88] Singh VK, Kalsan M, Kumar N, Saini A, Chandra R. Induced pluripotent stem cells: applications in regenerative medicine, disease modeling, and drug discovery. Front Cell Dev Biol. 2015; 3:2. doi: 10.3389/fcell.2015.00002

[89] Baraniak PR, McDevitt TC. Stem cell paracrine actions and tissue regeneration. Regen Med. 2010; 5:121-43.

[90] Clayton ZE, Tan RP, Miravet MM, Lennartsson K, Cooke JP, Bursill $\mathrm{CA}$, et al. Induced pluripotent stem cell-derived endothelial cells promote angiogenesis and accelerate wound closure in a murine excisional wound healing model. Biosci Rep. 2018; 38:BSR20180563. doi: 10.1042/BSR20180563

[91] Itoh M, Umegaki-Arao N, Guo Z, Liu L, Higgins CA, Christiano AM. Generation of 3D skin equivalents fully reconstituted from human induced pluripotent stem cells (iPSCs). PLoS One. 2013; 8:e77673. doi: 10.1371/journal.pone.0077673

[92] Gerami-Naini B, Smith A, Maione AG, Kashpur O, Carpinito G, Veves A, et al. Generation of induced pluripotent stem cells from diabetic foot ulcer fibroblasts using a nonintegrative Sendai virus. Cell Reprogram. 2016; 18:214-23.

[93] Zheng Y, Ji S, Wu H, Tian S, Zhang Y, Wang L, et al. Topical administration of cryopreserved living micronized amnion accelerates wound healing in diabetic mice by modulating local microenvironment. Biomaterials. 2017; 113:56-67.

[94] Lv Y, Ge L, Zhao Y. Effect and mechanism of SHED on ulcer wound healing in Sprague-Dawley rat models with diabetic ulcer. Am J Transl Res. 2017; 9:489-98.

[95] Badillo AT, Redden RA, Zhang L, Doolin EJ, Liechty KW. Treatment of diabetic wounds with fetal murine mesenchymal stromal cells enhances wound closure. Cell Tissue Res. 2007; 329:301-11.

[96] da Silva LP, Santos TC, Rodrigues DB, Pirraco RP, Cerqueira MT, Reis RL, et al. Stem cell-containing hyaluronic acid-based spongy hydrogels for integrated diabetic wound healing. J Invest Dermatol. 2017; 137:1541-51.

[97] Kwon DS, Gao X, Liu YB, Dulchavsky DS, Danyluk AL, Bansal M, et al. Treatment with bone marrow-derived stromal cells accelerates wound healing in diabetic rats. Int Wound J. 2008; 5:453-63.

[98] Ho JH, Tseng T-C, Ma W-H, Ong W-K, Chen Y-F, Chen M-H, et al. Multiple intravenous transplantations of mesenchymal stem cells effectively restore long-term blood glucose homeostasis by hepatic engraftment and $\beta$-cell differentiation in streptozocin-induced diabetic mice. Cell Transplant. 2012; 21:997-1009.

[99] Acosta L, Hmadcha A, Escacena N, Pérez-Camacho I, de la Cuesta A, Ruiz-Salmeron R, et al. Adipose mesenchymal stromal cells isolated from type 2 diabetic patients display reduced fibrinolytic activity. Diabetes. 2013: 62:4266-9.

[100] Wang Y, Han Z-B, Song Y-P, Han ZC. Safety of mesenchymal stem cells for clinical application. Stem Cells Int. 2012; 2012:652034. doi: 10.1155/2012/652034

[101] Rubio D, Garcia-Castro J, Martín MC, de la Fuente R, Cigudosa JC, Lloyd AC, et al. Spontaneous human adult stem cell transformation. Cancer Res. 2005; 65:3035-9.

[102] de la Fuente R, Bernad A, Garcia-Castro J, Martín MC, Cigudosa JC. Retraction: Spontaneous human adult stem cell transformation. Cancer Res. 2010; 70:6682.

[103] Yang S-S, Kim N-R, Park K-B, Do Y-S, Roh K, Kang K-S, et al. A phase I study of human cord blood-derived mesenchymal stem cell therapy in patients with peripheral arterial occlusive disease. Int. J Stem Cells. 2013; 6:37-44

[104] Qi L, Ahmadi AR, Huang J, Chen M, Pan B, Kuwabara H, et al. Major improvement in wound healing through pharmacologic mobilization of stem cells in severely diabetic rats. Diabetes. 2020; 69:699-712 